\title{
Study on Big Order Selling in the Framework of Strategic Marketing Analysis
}

\author{
Huang Dong \\ School of Applied Foreign Languages, Zhejiang Yuexiu University, Shaoxing, China
}

Email address:

563741855@qq.com

To cite this article:

Huang Dong. Study on Big Order Selling in the Framework of Strategic Marketing Analysis. Science Journal of Business and Management. Vol. 9, No. 1, 2021, pp. 39-46. doi: 10.11648/j.sjbm.20210901.14

Received: December 31, 2020; Accepted: January 19, 2021; Published: February 26, 2021

\begin{abstract}
This paper aimed at researching big order selling. In the past, there were very few researches based on this in China. Therefore, in this paper, relevant literatures will be reviewed again, and theories such as "strategic marketing analysis" and "4Ps", which were widely used in studying transaction costs and marketing tactics, will be employed to study the big order selling. In addition, research approaches of literature survey, case study, induction and comparative analysis have also been used. Generally speaking, big order selling is quite different from other orders; this paper explores how to successfully complete it. Firstly, this paper analyzes the characteristics, essences, and prerequisites of big order selling. Then, it introduces the theory of strategic marketing analysis. This paper's author points out that it is critical to build up a sort of adapting organizational structure, which further carries out the principle of relationship marketing and fleshly explains $4 \mathrm{P}$ tactics with the four kinds of costs derived from the theory of strategic marketing analysis. This paper also offers some concrete suggestions such as paying more attention to the process, emphasizing demand surveys, attaching importance to two types of costs: information searching cost and moral crises cost, using epilogue skills with caution, and so on. The findings of this study include following standpoints. First, the purpose of big order selling is to offer a systematic solution to thorny problems facing customers. Second, big order sales are typically complex purchases. Customers have high requirements for a company's prestige. Third, the ultimate total cost borne by customers play s a key role in big order sales. In short, this paper aims to provide some theoretical guidance and reference for those who specialize in big order selling.
\end{abstract}

Keywords: Big Order Selling, Relationship Marketing, Strategic Marketing Analysis

\section{Introduction}

The basic principles of marketing and sale apply to all kinds of products, but the operating details vary from product to product. This paper mainly analyzes the characteristics and strategies of big order selling.

Big order selling includes one purchase in fairly large quantities or selling something that has a hefty price tag. In this paper, we focus on the latter. A given company usually offers systematic approaches to problem-solving for customers. These approaches always feature very expensive equipment and sophisticated services ranging from massive defense systems, power plants, roads and bridges construction, large-scale consumer products to advanced strategic consulting services, etc. Big order selling differs in many ways from other common deals. There are lots of people involved in the buying decision process. It is also influenced by internal organizational, interpersonal, and individual factors as well as by external environmental factors.

At present, research on big order selling mainly focuses on the following aspects: (1) Increasing the success rate by improving after-sales service, such as manufacturers and retailers providing extended insurance services, who form a product-service supply chain to enhance customer satisfaction and promote big order sales. [2] (2) Improving the competence of sales staff through online and offline integration, which strengthens detailed management and the management of sales personnel. [5] (3) By firstly adjusting product strategies, it can be emphasized that these strategies should be transferred from balanced product portfolios to several core products, concentrate resources to create several top-selling items, and avoid excessive expansion of product lines. [1, 14]

These regular sales improvement strategies do not fully consider the particularities of big order sales. This paper will 
apply the theory "Strategic Marketing Analysis" which differs from traditional academic marketing theories to analyze them. "Strategic marketing analysis" includes four kinds of costs: explicit unit benefit cost, information searching cost, moral crises cost, and exclusive binding cost. This paper combines analyses of these four kinds of costs with the process of big order selling and points out that high transaction cost is the main cause that prevents big order selling from being successfully completed, and reducing these costs is helpful to make it succeed. Thus, it provides a new perspective for the study of big order selling.

\section{The Characteristics of Big Order Selling}

The critical aspect of big order selling is to offer a systematic solution to troublesome problems facing customers; thus, customer satisfaction is improved. We should focus on the most basic level of products and services named the "core product," which addresses the question: What is the buyer really buying? The core product stands at the center of the total product. It consists of the core, problem-solving benefits that consumers seek when they buy a product or service. However, its name, parts, styling, features, packaging, and other attributes constitute the actual products which deliver the core benefit. Generally, we can find many alternatives to the tangible parts of a product. So, salespeople should put themselves in the customer's place, concern with what customers concern. These selling approaches center on consultancy and problem-solving. At the same time, salespeople represent customers to the company, acting inside the firm as "champions" of customers' interests. Buying on impulse is out of the question in big order selling. Customers would never place an order until they are made fully aware of the benefits that the product will provide to them. Another requirement is that they have full confidence in the vendor. Salespeople should be a friend to the customer as well as being persistent, enthusiastic, attentive, and-above all-honest. They are expected to assist customers in achieving success.
Customers will buy the product voluntarily only if the product is a facilitator to attain their goals. The features, functions, benefits should be converted into values easily understood to customers. A successful big order selling ends up being a win-win game. It serves as an "adhesive" between buyers and sellers, brings them into a community of common interests.

Big order sales usually face more complex buying decisions. The selling process is nerve-rackingly slow-it can take six months or even two years from the first sales presentation to the day the sale is announced. A given company heads up an extensive team of specialists-sales and service technicians, financial analysts, planners, engineers, senior executives-all dedicated to finding ways to satisfy customer needs. They constitute a cross-functional team. In some special sales, top leaders are also involved. For example, when the Chinese premier visits a foreign country, he often pitches sales of high-speed rail technologies and has been fruitful to date. Customers always procure through open bidding what they want. The would-be sellers must hammer out a detailed business plan in advance. Big order selling also involves a more professional purchasing effort. Often, it is done by trained purchasing agents who spend their working lives learning how to buy better. And it is not just business decisions, but political, economic, and other very subtle factors are taken into consideration.

\section{Big Order Selling in Strategic Marketing Analysis}

\subsection{The Theories of Strategic Marketing Analysis}

Traditional academic marketing theories constitute environment analyses, STP, and 4P-the classical frameworks. Nevertheless, the strategic marketing analysis theories proposed by Qiu Zhisheng (2003) have stronger explanation strength on big order selling. These theories centering on exchange issues based on transaction and agency cost have intersections and correlations with traditional marketing theories but have a significant difference. As shown below:

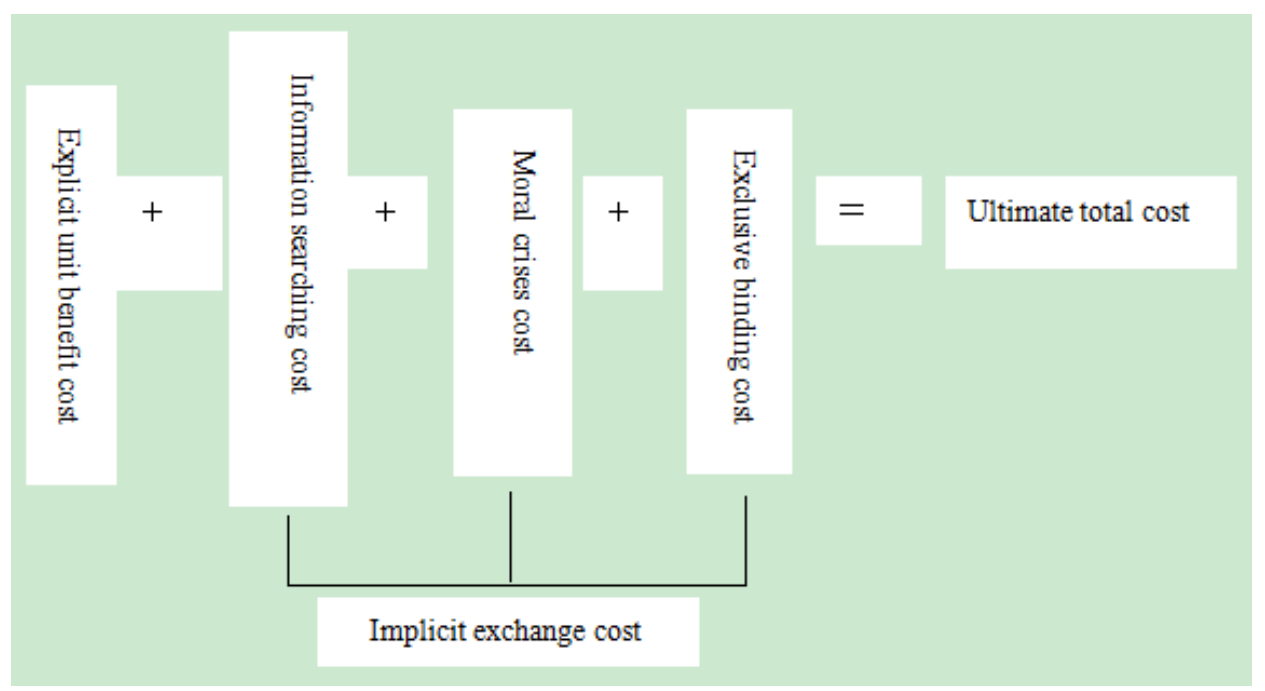

Figure 1. Framework of strategic marketing analysis. Source: [8]. 
The theory holds that by lowering the ultimate total cost will lead to more customer delivered value to a given company. And then the chances of closing the deal are good. Explicit unit benefit cost is the ratio of all customer cost to all customer get, also known as the price-performance ratio. Information searching cost is that because customers are not familiar with the product and the company, they have to invest lots of time, money, and energy searching relevant information to reduce information asymmetry. It is a considerable cost to them. Sometimes, the cost is too big to conclude the transaction. Moral crises cost is that a possible customer may worry that the product cannot reach the criteria set before the deal. When something unfortunate happens, especially during some situations that a specific contract does not cover, then it is possible that a given company would use their discretion toward their own favor rather than the customer's. As a result, customers will do what it takes to defend their interests, such as conducting very detailed due diligence, or designing a sophisticated contract, etc. Exclusive binding cost is that customers are concerned about losing tangible or intangible "asset specifity" derived from a potential deal if they are not in partnership with the company anymore. The concept of "asset specifity" had a great influence on later academic research. [12] In order not to let the asset dissipate, they cannot but keep the business relationship with each other. The "asset specifity" goes by diversified forms. One form is a special know-how. For example, if one had used Microsoft Office skillfully for many years, it becomes his/hers ingrained habit, which may make him/her be reluctant to use another new, similar office software. He/she may not think it is necessary to spend lots of time learning the new software. Other forms of "asset specifity" include physical equipment, intangible asset, psychological identification, etc. [8] The first cost is implicit, the latter three kinds of costs are explicit.

\subsection{Forge Adapting Organizational Structure}

A company requires customers-oriented flat organizational structure to attain successful big order selling. Different functional departments coordinated by unified marketing strategies should make concerted effort to react quickly and flexibly to customers' needs. Every department should focus on the interests of the whole company rather than their individual benefit. In rendering services to customers, all the staff transform into a sales team for the account. As shown in the Figure 2, marketing is closer to the customer than other function departments such as production, finance, sales, etc. However, it does not mean marketing is more important than other departments, it just means marketing is the interface between a company and its customer, serves as a bridge and bond between a variety of function departments and customers. As the management guru Peter Drucker put it: "[Marketing is] ... a central dimension of the entire business. It is the whole business seen from the point of view of its final result, that is, from the customer's point of view. Concern and responsibility for marketing must, therefore, permeate all areas of the enterprise."[15] By utilizing the value chain concept, purchasing, production, finance, logistics departments, etc., are required to make joint efforts to lower the ultimate cost significantly, thus more added value could be delivered to customers. Companies should both stick to these principles stated above and remain flexible, have entrepreneurship, refrain from red tape and office politics.

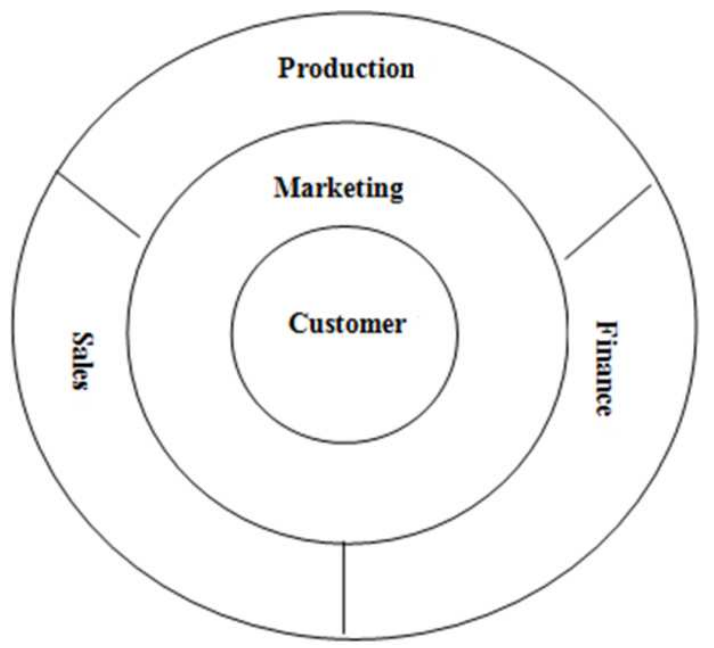

Figure 2. Marketing integrating other departments. Source: Guo Guoqing, General Theory of Marketing (8th Edition), Renmin University Press, 2020, p. 13. [4]

\subsection{Attach Importance to Relationship Marketing}

Beyond creating short-term transactions, marketers need to build long-term relationships with valued customers, distributors, dealers, and suppliers. They want to build strong economic and social ties by promising and consistently delivering high-quality products, good services, and fair prices. Increasingly, marketing is shifting from trying to maximize the profit on each individual transaction to building mutually beneficial relationships with consumers and other parties. The assumption is: build good relationships and profitable transactions will follow. Relationship marketing is oriented more toward the long term. The goal is to deliver long-term value to customers, and the measures of success are long-term customer satisfaction and retention. Beyond offering consistently high value and satisfaction, marketers can use a number of specific marketing tools to develop stronger bonds with consumers. First, a company might build value and satisfaction by adding financial benefits to the customer relationship. A second approach is to add social benefits as well as financial benefits. The third approach to building customer relationships is to add structural ties. [6]

Simply put, one of the characteristics of relationship marketing is the philosophy "want to make a deal, let us be friend first." Excellent relationship marketing can significantly lower information searching cost and moral crises cost. Big order sales involve far more dollars and potential risks than do usual transactions, so they are typically complex purchases. Customers have very high requirements for a company's reputation and brand image. The buying decision process is also the process of learning and getting 
reassurance. [13] Almost all of these purchases result in cognitive dissonance, or discomfort caused by postpurchase conflict. Companies cannot simply wait for dissatisfied customers to volunteer their complaints. Most unhappy customers never tell the company about their problems. Bad word of mouth often travels farther and faster than good word of mouth. It can quickly damage consumer attitudes about a company and its products. Therefore, a company should take the initiative in measuring customer satisfaction as soon as possible. It should set up systems that encourage customers to complain, solve the problems if there are any.

Why is it so important to satisfy the customer? Customer satisfaction is a key to building profitable relationships with consumers-to keeping and growing consumers and reaping their customer lifetime value. Satisfied customers talk favorably to others about the product, pay less attention to competing brands and advertising, and buy other products from the same company. More importantly, the transactions become straight rebuy, the buyer reorders something without any modifications on a routine basis by the purchasing department. That means low transaction cost.

\subsection{Marketing Mix Strategies in Big Order Sales}

\subsubsection{Product}

We will emphasize the fundamental level of the product"core benefit," which is the service or benefit the customer is really buying. People who buy an Apple iPad are buying more than just a tablet computer. They are buying entertainment, self-expression, productivity, and connectivity-a mobile and personal window to the world. Products include more than just tangible objects, broadly defined, products also include services just like equipment installation, training, etc.

In big order sales, there are always much complex details in the products. Customers usually cannot evaluate the products directly because of the lack of expertise. They must use the means named "peripheral route", in which attitude formation or change provokes much less thought and result from the consumer's association of a brand with either positive or negative peripheral cues. Peripheral cues for consumers include a celebrity endorsement, a credible source, or any object that generates positive feelings. That is to say, the brand prestige can lower the moral crises cost, which matters in big order sales. So, companies should invest heavily to create strong national or even global recognition and preference for their brand names. [11] It is a long-run systematic project. A brand with strong brand equity is a very valuable asset which is the outcome of consistently elaborate, arduous work.

\subsubsection{Price}

Price is not just a number on a tag, it is the total expenditure which includes time, energy, maintenance and the potential losses arising from the defects or unstable performance of the products during the entire product lifecycle. Tiny changes in unit price of product can lead to larger fluctuation in total amount of payment because of large volume. To buyers, both information searching cost and moral crises cost are very high. Companies should offer standard quotation of prices which make customers have stable expectations. Every offer of hardware, maintenance, training, etc. should be clearly explained. Initiating price changes, especially a price increase, may be resented by customers, dealers, and even their own sales force. Companies should state the quantity, time, reasons of the price change, and take measures to alleviate it. For example, companies should design sales promotion schemes to stimulate quicker or greater purchases. Sales promotion tools include free samples, frequency awards, coupons with a selling message, premiums, advertising specialties, contests and sweepstakes, consumer refund offers, and trade allowances. It is necessary to offer flexible financial arrangements just like allowing payment by instalments with zero down payment. Information on price changes should be imparted in advance, then the customers have a buffer period to adapt to it. There must be a customer-focused value proposition, a cogent reason why the target market should buy your product or service that could mitigate price increases to some extent. Obviously, perceived-value pricing suits products in big sales. The critical point of this pricing method is perceived value, not cost. Companies base their price on the customer's perceived value which is made up of a host of inputs such as the buyer's image of the product performance, the channel deliverables, the warranty quality, customer support, supplier's reputation, trustworthiness, and esteem.

\subsubsection{Place}

Conventional marketing channel is not suitable for big order sales. It consists of an independent producer, wholesaler(s), and retailer(s). Each is a separate business seeking to maximize its own profits, even if this goal reduces profits for the system as a whole. No channel member has complete or substantial control over other members. And vertical marketing system (VMS) would be fine. It includes the producer, wholesalers, and retailers acting as a unified system. One channel member, the channel captain, sometimes called a channel steward, owns or franchises the others or has so much power that they all cooperate. Stewards accomplish channel coordination without issuing commands or directives by persuading channel partners to act in the best interest of all. Extensive exchange of information and highly integration will be beneficial to buyers of complex products and systems. [10] Take HP as an example, its channel system includes value-added agents, value-added distributor, and independent software suppliers. The value-added agents are composed of systems integrators that cooperate with direct sales force and independent software developers to deliver the utmost possible value to customers. The keyword in this case is "value added." Professionalism and complexity surrounding products have high requirements on the qualifications of intermediaries. Furthermore, although the vertical marketing system make members become interwoven, every intermediary is not a dispensable link in the manufacturer-sponsored interest chain, but an entity with its own interests and functioning as an equal partner. Therefore, it 
is necessary to ensure the orderly distribution of benefits between manufacturers and channel members.

\subsubsection{Promotion}

Promotion in big order sales is quite distinct from that of general packaged consumer goods. In addition to advertising in professional journals and websites, the companies should pay more attention to annual trade exhibitions and conferences sponsored by relevant trade associations. Tens of thousands of people who take part in trade shows are highly relevant to many companies' businesses. Companies should find new sales opportunities, strengthen ties with regular customers, meet new customers, and promote new products at the fair. Give prospective customers a good impression of the company's products through paper and other audio-visual publicity materials to lay the groundwork for subsequent substantive negotiations.

Personal selling is also an important way of promoting a product as it can receive feedback in real time and help to get better communication. But personal selling is not done the way we usually think. For example, with those potential customers who have never been in contact, it is best not to knock on doors or dial telemarketing calls to ask them whether or not they need any products or services, because by asking "Do you want it?" usually does not work. Instead, it is better to get customers to ask the prospective company "Do you have it?" In this respect, McKincey \& Co. presents a good example. As the world's most prestigious consulting firm, it follows its own rule of "not selling." [3] This surprising rule in its culture stems from the fact that the company's founders were in a "proud" law and accounting firm before World War II. At that time, companies offering professional services were considered to be demeaning for advertising or soliciting business. So, they will never go out to knock on customers' doors, they just wait for the phone to ring, and it always does. This is due to McKinsey's unique marketing tactics. They will persistently publish books, academic papers, and research reports that are influential in many areas as well as publishing their own academic magazine McKinsey Quarterly. And they deliver it to clients and consultants who have left their office. Many of them now hold senior positions in potential clients' companies. Many of McKinsey's partners and managers are world-renowned experts in their area of expertise. They often make some insightful remarks at theme forums and industry summits, which leaves an impression on the public. In addition, they maintain a large network through which they keep contact with potential clients informally. For example, they will serve in charitable organizations, non-profit cultural organizations, etc. Many of its members are exactly executives of current or potential clients' companies. Their aim is to make sure that when a top executive encounters a tough problem, an idea would flash into his/her mind that he/she has no choice but to call McKinsey's local office for help. This unconventional selling is indeed superior, it can inspire some relevant companies.

During their early stages, companies must make some representative cases with far-reaching influence and help establish their reputation at any cost. Not only does that effectively reduce the implicit moral crises cost, but also create state-of-the-art selling strategies.

\subsubsection{Public Relations}

As mentioned above, the brand and corporate image is crucial in big order sales, and the functions of public relations (PR) include the protection and promotion of the corporate image as well as its brand. So, it is necessary to set up a full-time PR department to evaluate relevant public attitudes, identify the policies and procedures of an individual or an organization with the public interest, and plan and execute a program of action to earn public understanding and acceptance. That would foster goodwill accumulation. Good PR will bring in image premium, which will significantly increase the customer's perceived value of the company's products or services, and will directly reduce the explicit unit benefit cost if the price paid remains unchanged or even slightly increased. It will also have a positive effect on the information searching cost and moral crises cost. Potential customers will have high willingness to bind themselves to these companies. Those who believe that everything could be done as long as the quality of the product is good enough without spending energy on public relations are undoubtedly narrow-minded. It is a typical "marketing myopia." These misconceptions are common in companies that manufacture sophisticated specialized equipment. Companies must engage constructively with customers, suppliers and distributors, as well as with many latent publics who are interested in company.

Above all, companies should ultimately transcend the tools and utilitarian aspects of PR, pursue the true meaning of it, strive to become "corporate citizens," realize their long-term interests after creating value for customers and society. Companies should have the courage to assume responsibility, be enthusiastic about the public welfare, and stick to high standards of conduct. Then they will establish a good organizational image.

\section{Some Strategic Suggestions for Big Order Sales}

\subsection{Focus on Processes}

The success of big order sales depends on a complete process, not too much on one link of the chain. From the customer's point of view, the purchase process is divided into problem identification, requirement description, product specification determination, supplier searching, project solicitation, supplier selection, order specification determination, performance evaluation, and so on. Companies may consider the sales talks as a starting point. The four main stages of the talks are (1) initial contact, (2) demand surveys, (3) ability confirmation, and (4) advancement commitment. The task of the initial contact is to start sales talks, create a harmonious atmosphere, and provide a setting in which questions can be asked smoothly. Demand survey is the 
identification and definition of a customer's needs. Ability confirmation refers to clarifying how your product (solution) can meet the needs of your customers, and you ought to provide supporting evidences, such as representative cases, empirical demonstrations, etc. The advancement commitment allows sales negotiation to move substantially towards a final deal. All big order sales inevitably go through these four stages.

Among them, the demand surveys are the most important in the entire sales process, which corresponds to the problem identification and requirement description in the buyer's purchase process. [7] Efficient demand surveys require insight into the problems faced by potential customers. And companies should disaggregate and redefine the problems as "[a] proper definition of a problem is half done."1

\subsection{Demand Surveys}

The purpose of purchasing is to meet demand or solve a thorny problem. The potential losses caused by problem prompts customers to make purchase decisions. How does demand come into being? A prospective buyer will not have the need to replace the product in use when he is one hundred percent satisfied. But when there is something wrong with the existing product for some reason, the buyer wants to modify product specifications, prices, terms, or even suppliers. At this point, the "in" suppliers may become nervous and feel pressured to put their best foot forward to protect an account. But "out" suppliers may see the modified rebuy situation as an opportunity to make a better offer and gain new business. These occurrences would happen sooner in small order sales, and in big order sales the process would take months or even years. In order to better study customer demands, we need to divide them into two types: implicit and explicit. Implicit demands refer to the customer's clear statement of problems, difficulties, and dissatisfaction in the present situation. Such as "our current system does not match the output terminal", "loss rate is too high", "software is running too slowly", and so on. The explicit demands refer to the buyer's specific statement of his desire or intention to act. Just like "we need faster systems", "we're looking for more reliable devices", "we need faster software", and so on.

In small order sales, the difference between implicit and explicit demands has no discernible effect on the sales process, but that is essential in big order sales. The more implicit demands revealed in small order sales, the greater the probability of obtaining an order. But as business expands, the correlation between implicit demands and the likelihood of a final deal becomes weaker. For big orders, implicit need is only a starting point, and what you do to turn it into explicit demand is the key. In this transformation process, in addition to the urgency of need, the cost of solving the problem is an important factor. For example, pocket calculators achieved success soon after it was launched, because its compact appearance made people dissatisfied with the huge,

1 Philip Kotler. Marketing Management [M]. Shanghai: Shanghai People's Publishing House, 1999: 108. inconvenient desktop calculators at that time. In other words, it immediately creates an implicit demand. But another important reason which could not be ignored is that the new calculator also achieved enormous reduction in cost, which is about a fifteenth the price of the cumbersome calculator being replaced. Potential buyers have two reasons to buy, one is the implicit demand (or dissatisfaction with existing calculators), and the other is the benefit of low prices, which explain why it sold well.

Considering a value equation, one side of the equation is the urgency of solving the problem, the other side is the cost of doing that. Obviously, when the former is greater than the latter, sales happens. In small order sales, the cost of solving a problem (the price of a product or service) is usually low, and purchase motivation can be triggered simply by revealing some problems and implicit requirements. But in big sales, the cost of solving the problem is great, so there is a need to increase the weight on the other side of the value equation. That means, you need to influence customers' deeper needs to make the problems annoying them seem more serious and urgent.

So, how can implicit demands be transformed into explicit demands? There are two kinds of questions to be raised here: implication question and need-payoff question. There is an emotional criterion for distinguishing between these two types of questions, implication questions are always sad and negative, with some sense of "threatening," while the need-payoff questions are positive and make people happy, help relieve tension. For example, a typical implication question from the seller could be the following, "...because your equipment is out-of-date, production efficiency is very low, that leads to a steep increase in costs?" Buyer begins by stating "Exactly...". Followed by a need-payoff question, "How can production time be shortened?" Seller responds, "Adopt a new process, update equipment, and that will make us more competitive."

Implication questions are centered on predicament, those make the problems appear more serious, thereby making potential buyers feel sad. The need-payoff questions are solution-centered, which commit to questing for the meaning and value of solving the problems, so they make people feel very pleasant. Therefore, in big order sales, salespeople should ask potential customers sad questions first, and then ask pleasant questions. That would be better.

\subsection{Attach Importance to Two Types of Costs}

As mentioned earlier, there are two types of costs in big order sales: information searching cost and moral crises cost. These two kinds of costs constitute an important part of implicit costs in the framework of strategic marketing analysis. It is imperative for a company to reduce these two kinds of costs to achieve sales success, and they have a common key word: trust. In order to make customers trust the company and brand, we must reduce the information searching cost. First, there is a need for a clear and prominent position. A product's position is the way that the product is defined by consumers on important attributes - the place the product occupies in consumers' minds 
relative to competing products. Position provides a reason for purchase, and clear position enables marketers to have higher consistency when executing marketing mixes (4P). Manufacturers should try to identify a set of possible competitive advantages upon which to build a position, select the right competitive advantages, and differentiate them from those of competitors. It is best to show these cult attributes as the first one on the market. That way, consumers will be powerfully impressed. Second, companies will effectively communicate and deliver the chosen position to the target market. If you can let the buyers know the main selling points and benefits the instant they see a brand, they will not need more information to evaluate the brand. Companies can employ different communication channels, including regular customer visits, advertising, Internet, Weibo, WeChat, trade exhibition, mailing product information, and so on. Third, the positioning should be continuous and consistent for a long time, otherwise it is not conducive to the reduction of information searching costs. For example, when the toothpaste "crest" first went on sale, it stressed reducing cavities and innovatively invited the American Dental Association to endorse it, which is a great success. But later its position began to drift and be diversified, and concepts such as "warding off tooth decay," "fresh breath," "whitening" are emphasized at the same time, the image is increasingly blurred. Thus, it had steadily been losing its market share to other brands.

As for the marketing approaches to reduce the moral crises costs, most of them are relatively long-term. To establish a trustworthy image, we must rely on long-term word-of-mouth marketing, and require companies to have many good records which can make buyers have confidence in the products. First, to keep a potential customer's word, a feasible strategy is low commitment and high performance, which can significantly improve customer satisfaction. Truly take the best interests of customers as the starting point of consideration, adhering to the belief that only customers succeed first, the company can ultimately succeed. Do what it takes to maintain corporate image, have the courage to admit mistakes, and actively remedy them. To cultivate the teamwork spirit of employees, do not advocate individualistic heroism, cultivate customers' trust in the whole company rather than in specific employees. Second, standardize business processes and be transparent to reduce buyer oversight costs, especially for new companies that have not yet established a reputation. Look for several prestigious companies to cooperate with, which could help reassure customers. Seek the recommendations of credible, impartial testing units or being endorsed by reputable celebrities. Improve the product's quality control system. Introduce product quality control processes such as Six Sigma $(6 \sigma)$. Lastly, establish a crisis intervention system and proactively recall defective products.

\subsection{Use the Epilogue Technique with Caution}

Epilogue is an action taken by many salesmen near the end of the sales process. It is intended to imply and solicit a purchase promise so that the buyer can explicitly accept or reject it in the next statement. In essence, it is a means to put pressure on the customer. Typical epilogues are as follows:"Mr. Zhang, you know our product is obviously a good fit for you, if you could sign here (hypothetical epilogue)"; "If you wait until the next week, you may run out of stock and have to wait many months (ultimatum)"; "Do you want the project to start in September, or would you prefer it to start in November (selective epilogue)?"; "If you can't decide right away, I'll have to introduce it to another client who is eager to buy it (aggressive epilogue)." There is also a last resort type of epilogue called the "blank order epilogue," which means the salespeople act on their own to fill in the customer's information on the order, even if the customer does not reveal the intention of purchase.

Many salespeople prefer epilogue techniques, and many standardized sales training programs teach them this way. Epilogue techniques have been proven effective in many sales negotiations, mainly small order sales. For big order sales, however, epilogue techniques are just gimmicks which are ineffective, dangerous, and often self-defeating. The buyers of this kind of sale are very professional who know all the essential selling skills sellers might use. When you use epilogue techniques to simply win orders, customers cannot hide their dissatisfaction. It is understandable that the epilogue mentioned above is a means to put pressure on the client, which can lead to a decision. There is a psychological basis for this. The problem is that stress has a positive effect on tiny decisions, but it is counterproductive to big ones. [9] Big order sales require you to spend as much time with your customers as possible, not the other way around. Moreover, the more sophisticated and astute the buyers are, the more antipathetic they are to epilogue techniques.

In big sales, companies should avoid all superficial, stylized, mechanically copied "tricks" and do a good job to show their customers that they can truly create value for them.

\section{Conclusions}

What customers need from big order sales are systematic solutions to some burdensome problems facing themselves. We should focus on the "core product", which are the benefits the product will provide to customers. Establishing mutual confidence is indispensable prerequisite for big order sales, which could only be win-win game. Big order selling involves a much more complicated purchasing effort. Moreover, it is not just business decisions, other intricate factors such as relationships, even politics will also be taken into consideration.

The findings of this study reveal that the key variable to conclude the big order transaction is the ultimate total cost borne by customers. The ultimate total cost consists of explicit unit benefit cost, information searching cost, moral crises cost, exclusive binding cost. The lower the total cost, the greater the likelihood of success. Therefore, we should take steps such as forging adapting organizational structure, applying relationship marketing and marketing mix strategies, etc. to coordinate the four types of costs. Each of these costs plays an important role. There are also some very specific 
suggestions at the operational level. The suggestions include focusing on processes, implementing demand surveys, paying close attention to information searching cost and moral crises cost, properly using the epilogue techniques, and so on.

In this study, however, there are two limitations. First, research methods are not diverse enough. Future research could employ a variety of methods such as grounded theory, focus group discussions, statistic analysis and survey experiment, etc. Second, the findings are mainly based on the analysis of "strategic marketing analysis" theory, whether the findings are applicable in every industry needs more verification. Hence, it is suggested that more theories are employed in future research and are analyzed in more diverse perspectives. That will be more constructive and precious for those big order selling practitioners.

\section{Acknowledgements}

This research is partially supported by Research Project of Higher Educational Teaching Reform of Zhejiang Province under grant No. jg20190506.

\section{References}

[1] Adrian J. Slywotzky. Find Profit Zone [M]. Beijing: Citic Press, 2018.

[2] Dan Bin. A Study on the Sales Strategy of Extended Insurance Service in the Supply Chain of Product Service [J]. Management Review, 2020.

[3] Essen Russell. The McKinsey Method [M]. Beijing: Huaxia Press, 2001.
[4] Guo Guoqing. General Theory of Marketing (8th Edition) [M]. Renmin University of China Press, 2020.

[5] Li Yulong. An Analysis of the Opportunities and Challenges Facing Sales Enterprises under New Normal [J]. Chinese and Foreign Entrepreneurs, 2020.

[6] Philip Kotler. Kotler Marketing Strategy [M]. Beijing: Citic Press, 2007.

[7] Philip Kotler. Marketing Management (9th edition) [M]. Shanghai: Shanghai People's Publishing House, 1999.

[8] Qiu Zhisheng. Strategic Marketing Analysis-Framework and Practical Application [M]. Shanghai: Fudan University Press, 2003.

[9] Neil Rackham. Sales Giant - Big Order Sales Training Manual [M]. Beijing: Enterprise Management Press, 2006.

[10] Stefan Wuyts, Stefan Stremersch, Christophe Van Den Bulte, Philip Hans Franses. Vertical Marketing Systems for Complex Products: A Triadic Perspective [J]. Journal of Marketing Research, 2004 (41).

[11] Wang Yunhong. Four Misconceptions of Large Single Product Strategy [J]. Sales \& Marketing, 2013, 12.

[12] Williamson, Oliver E. The Economic Institutions of Capitalism: Firms, Markets, Relational Contracting [M]. New York: The Free Press, 1985.

[13] Yang Shuyun. What to Do after the Big Order Sale [J]. Knowledge Economy, 2011, 02.

[14] ZhangJi. Benefits of Large Items [J]. Sales and Marketing Journal Management Edition, 2017.

[15] Peter Drucker. Management: Tasks, Responsibilities, Practices [M]. New York: Harper \& Row, 1973. 